\title{
A New Numerical Solution of Maxwell Fluid over a Shrinking Sheet in the Region of a Stagnation Point
}

\author{
S. S. Motsa, ${ }^{1}$ Y. Khan, ${ }^{2}$ and S. Shateyi ${ }^{3}$ \\ ${ }^{1}$ School of Mathematical Sciences, University of KwaZulu-Natal, Private Bag X01, Scottsville, \\ Pietermaritzburg 3209, South Africa \\ ${ }^{2}$ Department of Mathematics, Zhejiang University, Hangzhou 310027, China \\ ${ }^{3}$ Department of Mathematics, University of Venda, P Bag X5050, Thohoyandou 0950, South Africa \\ Correspondence should be addressed to S. Shateyi, stanford.shateyi@univen.ac.za
}

Received 29 March 2012; Revised 5 July 2012; Accepted 10 July 2012

Academic Editor: Anuar Ishak

Copyright (C) 2012 S. S. Motsa et al. This is an open access article distributed under the Creative Commons Attribution License, which permits unrestricted use, distribution, and reproduction in any medium, provided the original work is properly cited.

\begin{abstract}
The mathematical model for the incompressible two-dimensional stagnation flow of a Maxwell fluid towards a shrinking sheet is proposed. The developed equations are used to discuss the problem of being two dimensional in the region of stagnation point over a shrinking sheet. The nonlinear partial differential equations are transformed to ordinary differential equations by firsttaking boundary-layer approximations into account and then using the similarity transformations. The obtained equations are then solved by using a successive linearisation method. The influence of the pertinent fluid parameters on the velocity is discussed through the help of graphs.
\end{abstract}

\section{Introduction}

Many engineering fluid mechanical problems have been solved using this boundary-layer theory rendering results which compare well with experimental observations-at least as far as Newtonian fluids are concerned. In spite of the success of this theory for Newtonian fluids, an extension of the theory to non-Newtonian fluids has turned out to be a rather formidable task [1-3]. The main difficulty in reaching to a general boundary-layer theory for nonNewtonian fluids lies obviously in the diversity of these fluids in their constitutive behavior, simultaneous viscous, and elastic properties such that differentiating between those effects which arise as a result of a fluid's shear-dependent viscosity from those which are attributable to the fluid's elasticity becomes virtually impossible. But some mathematical models have been proposed to fit well with the experimental observations. The simplest model for the rheological effects of viscoelastic fluids is the Maxwell model where the dimensionless relaxation time is small. However, in some more concentrated polymeric fluids the Maxwell 
model is also used for large dimensionless relaxation time. Some recent investigations which deal with the flows of Maxwell fluids are given in [4-8].

The viscous flows due to a stretching sheet have attracted the attention of many researchers. This is due to their several applications in polymer processing industries, environmental pollution, biological process, aerodynamic extrusion of plastic sheets, glass fiber production of the boundary layer along a liquid film and condensation process, the cooling, and/or drying of paper and textiles. In 1966, Erickson et al. [9] investigated the problem of heat and mass transfer on a moving continuous plate with suction and injection. In view of above applications, Crane [10] extended Sakiadis [11,12] study of boundary layer flow for stretching sheet. The literature on the stretching sheet topic is quite extensive and hence cannot be described in detail. However, some most recent works of eminent researchers regarding the flow over a stretching sheet may be mentioned in the studies [1320]. Literature survey indicates that no attention has been given to the shrinking flow [2125] for Maxwell fluid for two-dimensional stagnation flow and axisymmetric stagnation flow towards an axisymmetric shrinking over a shrinking sheet. There are few situations like rising shrinking balloon, and so forth, the standard stretching phenomena is not useful therefore, the shrinking phenomena are used.

Wang [26] has discussed the stagnation flow towards a shrinking sheet. According to him, solution does not exist for a shrinking sheet in an otherwise still fluid since vorticity could not be confined in a boundary layer. However, in the presence of stagnation flow to contain the vorticity, similarity solution may exist. Mention may be made to the works of [27-33]. The objective of this paper is two-fold: first, to formulate the Maxwell fluid for two-dimensional stagnation flow towards a shrinking sheet; second, to calculate the numerical solution of transformed nonlinear ordinary differential equations via the successive linearisation method. The numerical results for boundary layer Maxwell fluid in the stagnation flow induced by shrinking sheet by means of SLM are yet not available in the literature.

\section{Mathematical Modeling}

For the steady, incompressible stagnation flow equations for Maxwell fluid towards a shrinking sheet are of the following form:

$$
\begin{gathered}
\frac{\partial u}{\partial x}+\frac{\partial v}{\partial y}+\frac{\partial w}{\partial z}=0 \\
u \frac{\partial u}{\partial x}+w \frac{\partial u}{\partial z}+\lambda\left(u^{2} \frac{\partial^{2} u}{\partial x^{2}}+2 u w \frac{\partial^{2} u}{\partial x \partial z}+w^{2} \frac{\partial^{2} u}{\partial z^{2}}\right)=U \frac{d U}{d x}+v \frac{\partial^{2} u}{\partial z^{2}}
\end{gathered}
$$

where $u, v$, and $w$ are the velocity components along $x, y$, and $z$-axis, $U=a x$ is the free stream velocity, $v$ is the kinematic viscosity, and $\lambda$ is the relaxation time.

The boundary conditions for the present problem are given by

$$
\begin{aligned}
& u=b(x+c), \quad w=0, \quad \text { at } y=0, \\
& u=a x, \quad w=-a z, \quad \text { as } y \longrightarrow \infty,
\end{aligned}
$$

where $a$ is the strength of the stagnation flow, $b$ is stretching rate (shrinking is $b<0$ ), and $c$ is the location of the stretching origin. 
We define the following similarity variables [26]:

$$
\eta=\sqrt{\frac{a}{v}} z, \quad u=a x f^{\prime}(\eta)+b \operatorname{ch}(\eta), \quad v=0, \quad w=-\sqrt{a v} f(\eta)
$$

Equation (2.1) is satisfied identically, and (2.2) yields

$$
\begin{gathered}
f^{\prime \prime \prime}+f f^{\prime \prime}-f^{\prime 2}+1-\beta\left(f^{2} f^{\prime \prime \prime}-2 f f^{\prime} f^{\prime \prime}\right)=0, \\
h^{\prime \prime}+f h^{\prime}-f^{\prime} h-\beta\left(f^{2} h^{\prime \prime}-f h f^{\prime \prime}\right)=0 .
\end{gathered}
$$

Here primes denote differentiation with respect to $\eta$, and $\beta=\lambda_{c}$ is the Deborah number. The boundary conditions are

$$
\begin{gathered}
f(0)=0, \quad f^{\prime}(0)=\alpha, \quad f^{\prime}(\infty)=1, \\
h(0)=1, \quad h(\infty)=0,
\end{gathered}
$$

where $\alpha=b / a, \alpha>0$, and $\alpha<0$ correspond to stretching and shrinking sheets, while $\alpha=0$ correspond to planar stagnation flow towards a stationary sheet. Moreover, when $\alpha=1$, the flow will be with no boundary layer.

\section{Solution Method}

In this section the implementation of the successive linearisation method (SLM) is solving the governing boundary value problems. The SLM (see, e.g., [34-38] for details) is based on transforming the governing nonlinear boundary value problem into an iterative scheme made up of linear differential equations which are subsequently solved using analytical or numerical methods wherever possible. Details of the formulae for implementing the SLM in one dimensional equations are given in [36].

In applying the SLM on (2.5), we set

$$
f(\eta)=f_{i}(\eta)+\sum_{m=0}^{i-1} f_{m}(\eta), \quad i=1,2,3, \ldots
$$

where $f_{i}$ are unknown functions that are obtained by iteratively solving the linearized version of the governing equations assuming that $f_{i}(0 \leq m \leq i-1)$ are known from previous iterations. The algorithm starts with an initial approximation $f_{0}(\eta)$ which is chosen to satisfy the boundary conditions (2.7). A suitable initial guess in this example is

$$
f_{0}(\eta)=\eta+(\alpha-1)\left(1-e^{-\eta}\right)
$$

To investigate the SLM application on (2.5), we write the equation as

$$
\mathcal{L}\left(f, f^{\prime}, f^{\prime \prime}, f^{\prime \prime \prime}, f^{\prime \prime \prime \prime}\right)+\mathcal{N}\left(f, f^{\prime}, f^{\prime \prime}, f^{\prime \prime \prime}, f^{\prime \prime \prime \prime}\right)=0,
$$


where

$$
\begin{gathered}
\mathcal{L}(\cdots)=f^{\prime \prime \prime}, \\
\mathcal{N}(\cdots)=f f^{\prime \prime}-f^{\prime 2}+1-\beta\left(f^{2} f^{\prime \prime \prime}-2 f f^{\prime} f^{\prime \prime}\right) .
\end{gathered}
$$

Substituting (3.1) in (2.5) and linearising the resulting equation, we obtain the following governing equation:

$$
f_{i}^{\prime \prime \prime}+a_{0, i-1} f_{i}^{\prime \prime \prime}+a_{1, i-1} f_{i}^{\prime \prime}+a_{2, i-1} f_{i}^{\prime}+a_{3, i-1} f_{i}=r_{i-1}
$$

subject to the boundary conditions

$$
f_{i}(0)=0, \quad f_{i}^{\prime}(0)=0, \quad f_{i}^{\prime}(\infty)=0,
$$

where $a_{p, i-1}(p=0,1, \ldots, 3)$ are defined using $\tilde{f}_{m}=\sum_{m=0}^{i-1} f_{m}$ (for compactness) as

$$
\begin{gathered}
a_{0, i-1}=-\beta \tilde{f}_{m}^{2}, \\
a_{1, i-1}=\tilde{f}_{m}\left(1+2 \tilde{f}_{m}^{\prime}\right), \\
a_{2, i-1}=-2 \tilde{f}_{m}^{\prime}+2 \beta \tilde{f}_{m} \tilde{f}_{m}^{\prime \prime}, \\
a_{3, i-1}=\tilde{f}_{m}^{\prime \prime}-2 \beta \tilde{f}_{m} \tilde{f}_{m}^{\prime \prime \prime}+2 \beta \tilde{f}_{m}^{\prime} \tilde{f}_{m}^{\prime \prime} .
\end{gathered}
$$

We solve (3.5) using the Chebyshev spectral collocation method. To allow for numerical implementation of the spectral method, the physical region $[0, \infty)$ is truncated to $[0, L]$, where $L$ is chosen to be sufficiently large. The truncated region is further transformed to the space $[-1,1]$ using the transformation

$$
\xi=\frac{2}{L} \eta-1
$$

As with any other numerical approximation method some sort of discretization is introduced to the interval $[-1,1]$. To this end, we choose the Gauss-Lobatto collocation points (see, e.g., [39-42]) to define the nodes in $[-1,1]$ as

$$
\xi_{j}=\cos \left(\frac{\pi j}{N}\right), \quad j=0,1, \ldots, N
$$

where $(N+1)$ is the number of collocation points. The essence of the Chebyshev spectral collocation method is the concept of a differentiation matrix $D$. The differentiation matrix 
maps a vector of the function values $\mathbf{F}=\left[f\left(\xi_{0}\right), \ldots, f\left(\xi_{N}\right)\right]^{T}$ at the collocation points to a vector $\mathbf{F}^{\prime}$ defined as

$$
\mathbf{F}^{\prime}=\sum_{k=0}^{N} D_{k j} f\left(\xi_{k}\right)=D \mathbf{F}
$$

In general, the derivative of order $p$ for the function $f(\xi)$ can be expressed by

$$
f^{(p)}(\xi)==D^{p} \mathbf{F}
$$

The entries of $D$ can be computed in different ways (see, e.g., [39-42]). In this work we use the method proposed by Trefethen [42] in the cheb.m Matlab m-file. Thus, applying the spectral method, with derivative matrices on linearised equations (3.5) and (3.6) leads to the following linear matrix system:

$$
\mathbf{A}_{i-1} \mathbf{F}_{i}=\mathbf{R}_{i-1}
$$

with the boundary conditions

$$
f_{i}\left(\xi_{N}\right)=0, \quad \sum_{k=0}^{N} \mathbf{D}_{N k} f_{i}\left(\xi_{k}\right)=0, \quad \sum_{k=0}^{N} \mathbf{D}_{0 k} f_{i}\left(\xi_{k}\right)=0, \quad \sum_{k=0}^{N} \mathbf{D}_{0 k}^{2} f_{i}\left(\xi_{k}\right)=0
$$

where

$$
\mathbf{A}_{i-1}=\mathbf{D}^{3}+\mathbf{a}_{0, i-1} \mathbf{D}^{3}+\mathbf{a}_{1, i-1} \mathbf{D}^{2}+\mathbf{a}_{2, i-1} \mathbf{D}+\mathbf{a}_{3, i-1}
$$

and $\mathbf{D}=(2 / L) D, \mathbf{a}_{s, i-1}(s=0,1, \ldots, 3)$ are $(N+1) \times(N+1)$ diagonal matrices with $a_{s, i-1}\left(\xi_{j}\right)$, on the main diagonal and

$$
\mathbf{F}_{i}=f_{i}\left(\xi_{j}\right), \quad \mathbf{R}_{i}=r_{i}\left(\xi_{j}\right), \quad j=0,1, \ldots, N
$$

After imposing the boundary conditions (3.13), the solutions for $f_{i}$ are obtained by iteratively solving the system (3.12) starting from the initial approximation (3.2). Once the solution for $f(\eta)$ has been found from solving (3.13), the Chebyshev pseudospectral method is directly applied on (2.6) which is now linear. This gives the following:

$$
\mathbf{B H}=\mathbf{S}
$$

with the boundary conditions

$$
h\left(\xi_{N}\right)=1, \quad h\left(\xi_{0}\right)=0,
$$


Table 1: Comparison of the results of Wang [26] against the present SLM results for the case when $\alpha>0$ and $\beta=0$.

\begin{tabular}{lccccccc}
\hline$\alpha$ & (Iter.) & 0 & 0.1 & 0.2 & 1 & 2 & 5 \\
\hline & 1 & 1.243490 & 1.156422 & 1.059691 & 0.000000 & -1.861844 & -9.792476 \\
& 2 & 1.232631 & 1.146594 & 1.051154 & 0.000000 & -1.887189 & -10.243081 \\
$f^{\prime \prime}(0)$ & 3 & 1.232588 & 1.146561 & 1.051130 & 0.000000 & -1.887307 & -10.264639 \\
& 4 & 1.232588 & 1.146561 & 1.051130 & 0.000000 & -1.887307 & -10.264749 \\
& 5 & 1.232588 & 1.146561 & 1.051130 & 0.000000 & -1.887307 & -10.264749 \\
Reference [26] & & 1.232588 & 1.14656 & 1.05113 & 0.000000 & -1.88731 & -10.26475 \\
\hline$h^{\prime}(0)$ & & -0.811301 & -0.863452 & -0.913303 & -1.253314 & -1.589567 & -2.338099 \\
Reference [26] & & -0.811301 & -0.86345 & -0.91330 & -1.25331 & -1.58957 & -2.33810 \\
\hline
\end{tabular}

Table 2: Comparison of the results of Wang [26] against the present SLM results for the case when $\alpha<0$ and $\beta=0$.

\begin{tabular}{lccccccc}
\hline$\alpha$ & (Iter.) & -0.25 & -0.5 & -0.75 & -1 & -1.15 & -1.15 (2nd Solution) \\
\hline & 1 & 1.413934 & 1.504746 & 1.494801 & 1.352084 & 1.182769 & -0.267033 \\
& 2 & 1.402301 & 1.495718 & 1.489318 & 1.329038 & 1.088692 & 0.028223 \\
& 3 & 1.402241 & 1.495670 & 1.489298 & 1.328817 & 1.082272 & 0.109614 \\
& 4 & 1.402241 & 1.495670 & 1.489298 & 1.328817 & 1.082231 & 0.116650 \\
Reference [26] & 5 & 1.402241 & 1.495670 & 1.489298 & 1.328817 & 1.082231 & 0.116702 \\
\hline$h^{\prime}(0)$ & 1.40224 & 1.49567 & 1.48930 & 1.32882 & 1.08223 & 0.116702 \\
Reference [26] & & -0.668573 & -0.501448 & -0.293763 & 0 & 0.297995 & 0.2763445 \\
\hline
\end{tabular}

where

$$
\mathbf{B}=\mathbf{D}^{2}-\beta \mathbf{f}^{2} \mathbf{D}^{2}+\mathbf{f D}-\mathbf{f}^{\prime}+\beta \mathbf{f f}^{\prime \prime}=0
$$

and $\mathbf{H}=h\left(\xi_{j}\right), \mathbf{S}$ is a vector of zeros, and all vectors in (3.18) are converted to a diagonal matrix. The boundary conditions (3.17) are placed on the first and last rows of $\mathbf{B}$ and $\mathbf{S}$.

\section{Results and Discussion}

In this section we give results obtained by the successive linearisation method for selected values of important parameters of the Maxwell fluid over a shrinking sheet in the region of a stagnation point. To check the accuracy of the SLM employed in the current study, a comparison of the initial values is made with published results from literature. In particular, comparison is made with the skin friction coefficient $f^{\prime \prime}(0)$ results and results for $h^{\prime}(0)$ of Wang [26] for the special case when $\beta=0$. Tables 1 and 2 give the results for the friction coefficient $f^{\prime \prime}(0)$ and $h^{\prime}(0)$ for $\alpha>0$ and $\alpha<0$, respectively. It can be seen from these tables that the present SLM results are in excellent agreement with those of Wang [26]. We also observe that SLM results converge rapidly with full convergence to the numerical results of [26] reached after only 3 or 4 iterations. This confirms the validity of the SLM method for solving the problem under study. 

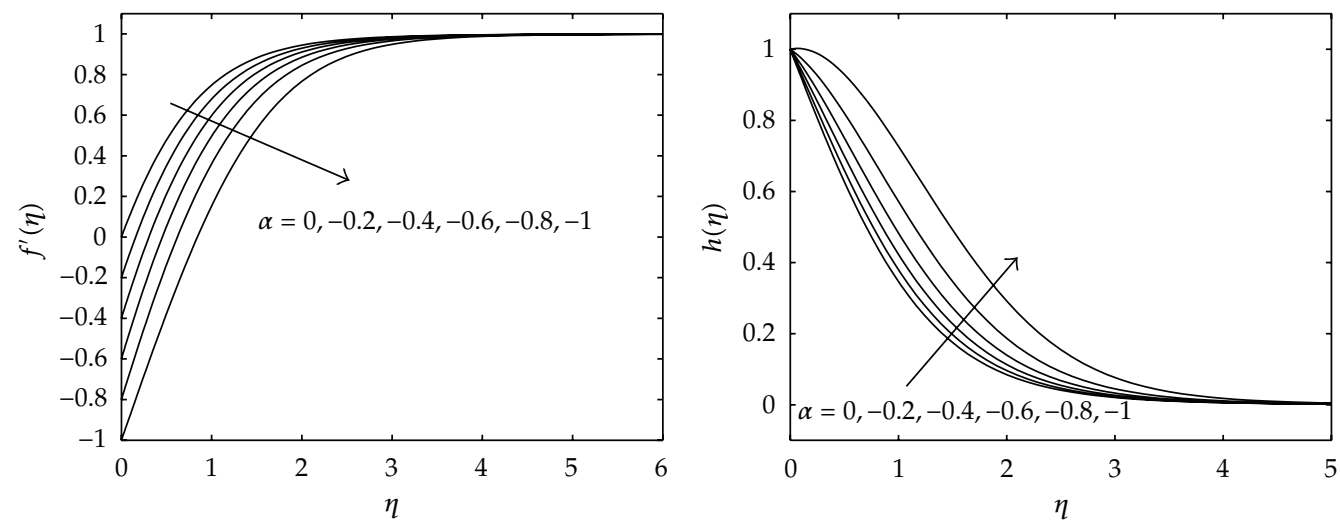

Figure 1: Effect of the shrinking parameter $\alpha(\alpha<0)$ on $f^{\prime}(\eta)$ and $h(\eta)$ when $\beta=-0.2$.
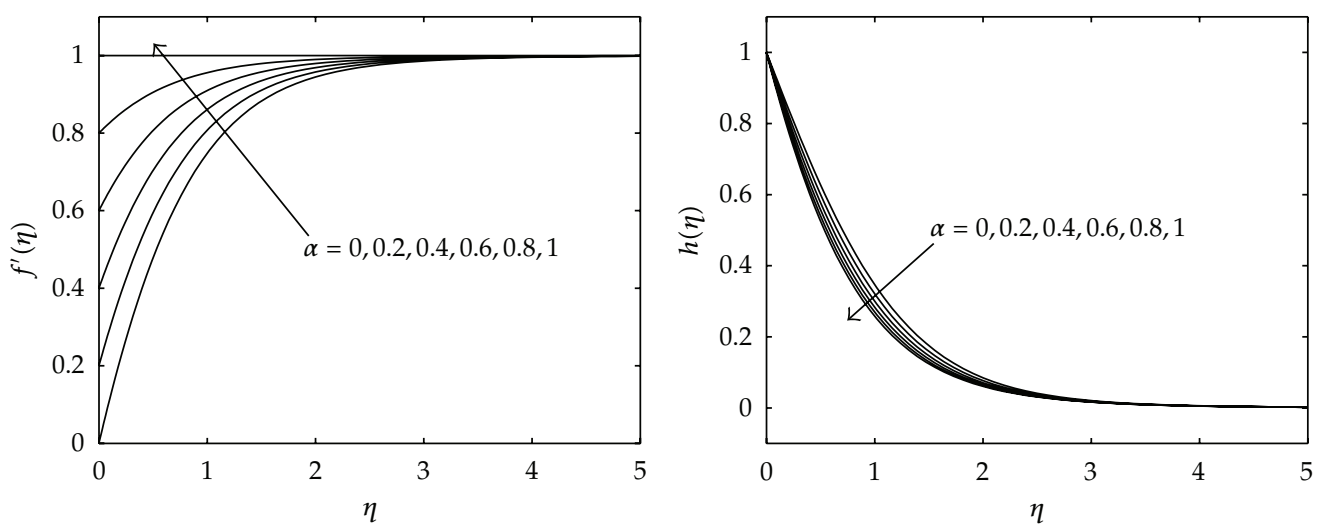

Figure 2: Effect of the stretching parameter $\alpha(\alpha>0)$ on $f^{\prime}(\eta)$ and $h(\eta)$ when $\beta=-0.2$.

For some negative values of $\alpha$ it was found that multiple solutions exist. To generate the multiple solution different initial approximations were used as first guesses of the SLM iteration scheme. The multiple solutions for $f^{\prime \prime}(0)$ and $h^{\prime}(0)$ are resolved when $\alpha=-1.15$ and illustrated in Table 2 for the case $\beta=0$. Again, good agreement with the results of [26] is observed. The presence of dual solutions has also been observed in related investigations stagnation flow in the presence of shrinking, (see, e.g., [26-33]).

The effect of the shrinking parameter $\alpha(\alpha<0)$ of $f^{\prime}(\eta)$ and $h(\eta)$ is depicted on Figure 1 . We observe that shrinking of the sheet decelerates the fluid flow. Figure 2 shows the effect of the stretching parameter $\alpha(\alpha>0)$ on $f^{\prime}(\eta)$ and $h(\eta)$. We observe that the boundary layer thickness is decreased when values of $\alpha$ increase. Physically, this can be explained as follows: for fixed values of $a$ corresponding to the stretching of the sheet, an increase in $b$ implies an increase in straining motion near the stagnation region resulting in the increased acceleration of the external stream, and this leads to the thinning of the boundary layer.

The influence of the Deborah number $\beta$, for both the shrinking $(\alpha<0)$ and stretching $(\alpha>0)$, can be seen from Figures 3 and 4 . As shown in these figures, the velocity decreases with the increase of the Deborah number $\beta$ or the relaxation time. 

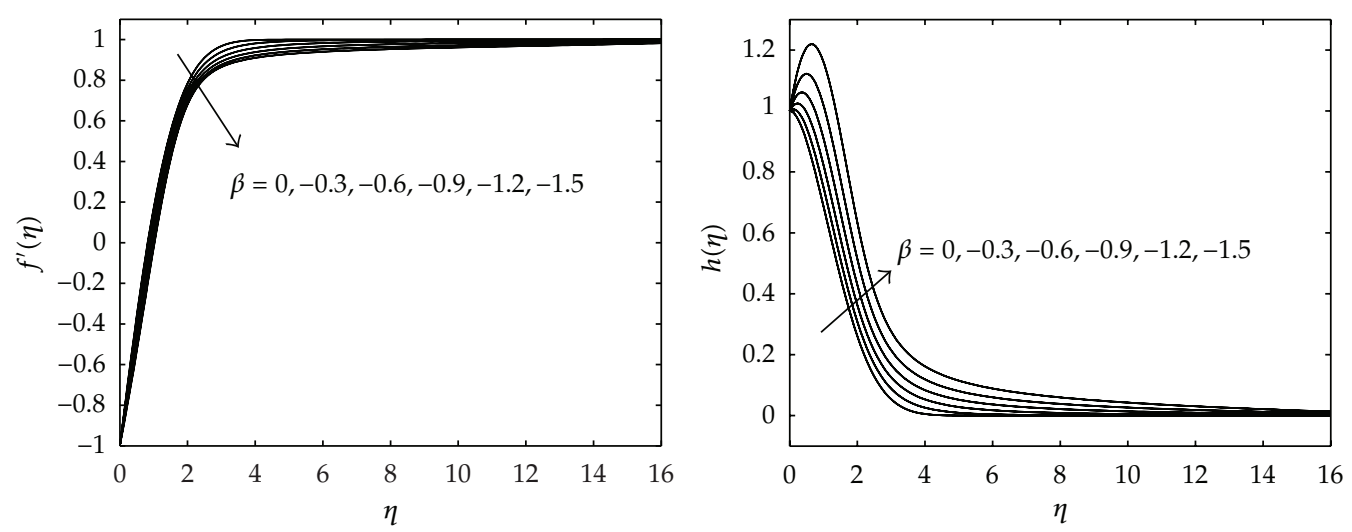

Figure 3: Effect of the parameter $\beta$ on $f^{\prime}(\eta)$ and $h(\eta)$ when $\alpha=-1$.
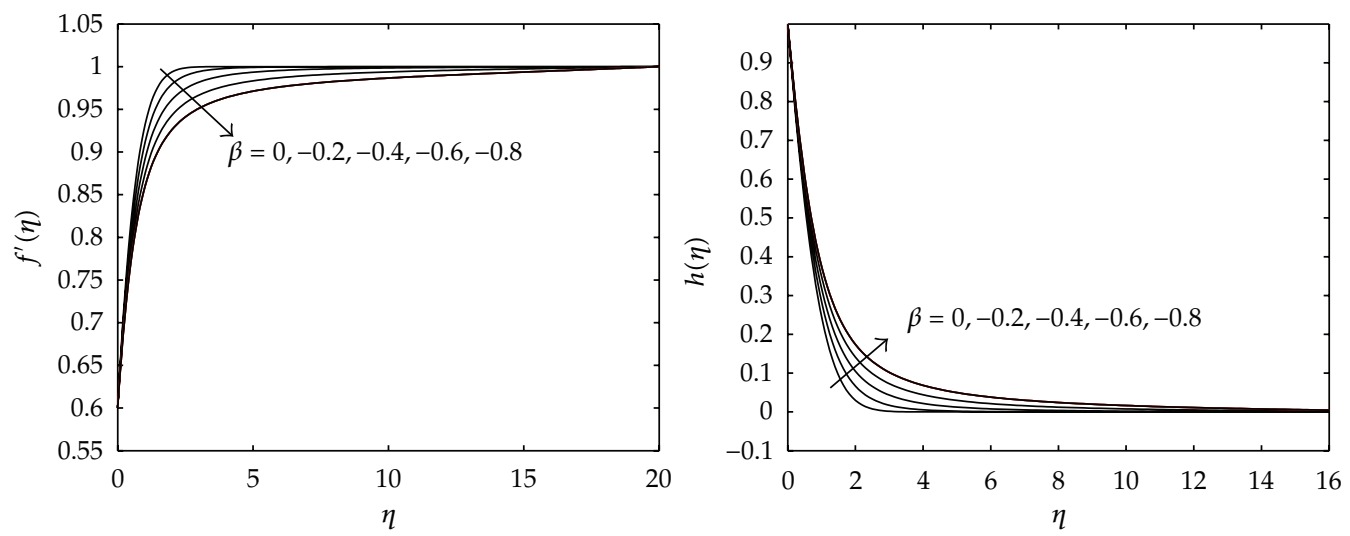

Figure 4: Effect of the parameter $\beta$ on $f^{\prime}(\eta)$ and $h(\eta)$ when $\alpha=0.6$.

Figure 5 depicts the existence of the dual solutions for the velocity profiles. The effects of $\alpha$ and $\beta$ on $f^{\prime \prime}(0)$ and $h^{\prime}(0)$ are shown on Figure 6 . In this figure, we clearly observe the domain of valid values for $\alpha$ which give rise to multiple solutions.

\section{Concluding Remarks}

The two-dimensional equations for Maxwell fluid are derived in this paper. The boundary layer in the region of stagnation point over a two-dimensional shrinking sheet is discussed for Maxwell fluid. The similarity transformations are used to transform the partial differential equations to ordinary ones, and hence a numerical solution is obtained using the SLM. The novel technique was compared against previous studies and excellent agreement was observed. The study also confirmed the existence of a dual solution. We also observed the relatively rapid convergence of the SLM. The results are presented graphically and the effects of the parameters are discussed. 

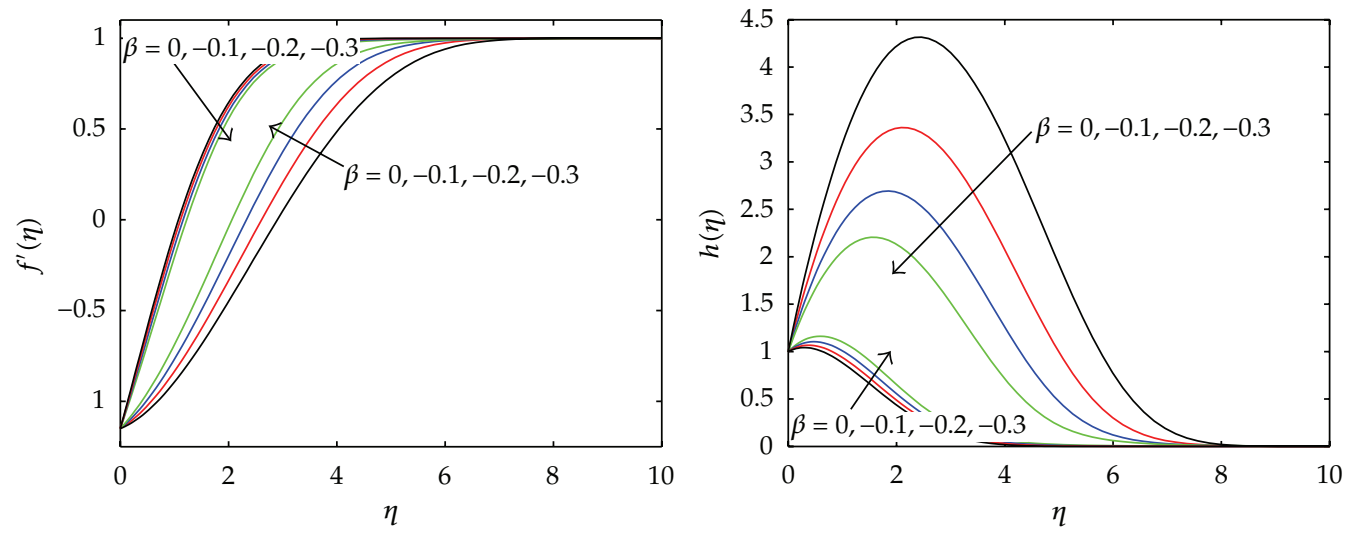

Figure 5: Dual solutions: effect of the parameter $\beta$ on $f^{\prime}(\eta)$ and $h(\eta)$ when $\alpha=-1.15$.
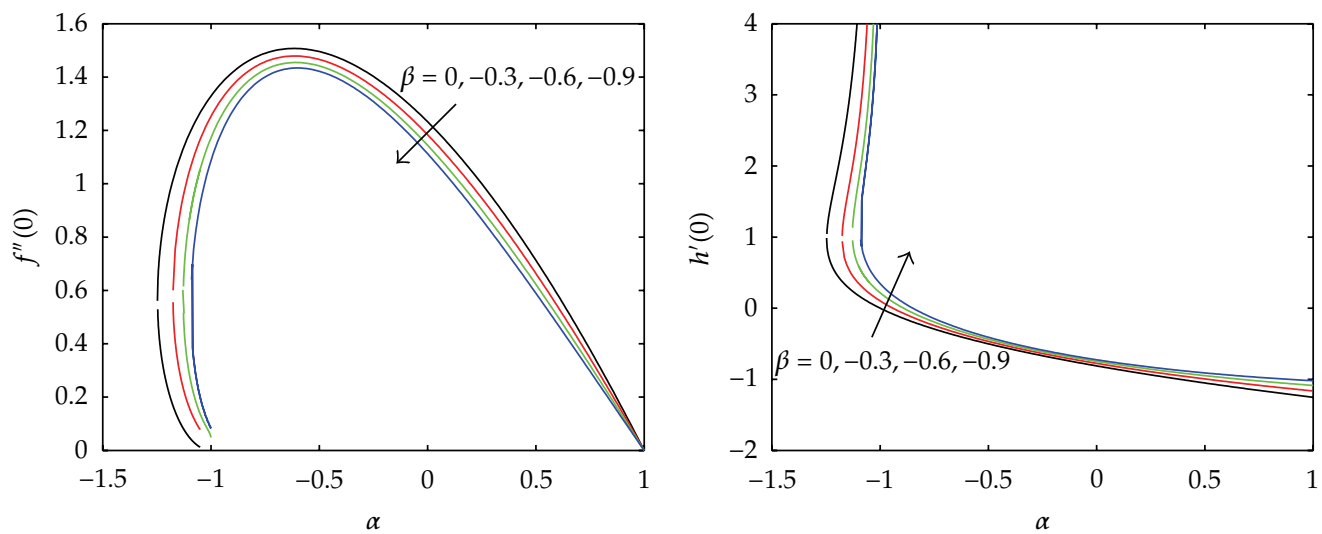

Figure 6: Graphs of $f^{\prime \prime}(0)$ and $h^{\prime}(0)$ against $\alpha$ for different values of $\beta$.

\section{Acknowledgments}

The authors wish to acknowledge financial support from the University of Venda and the National Research Foundation (NRF).

\section{References}

[1] M. H. Davies, "A note on elastico-viscous boundary layer flows," Zeitschrift für Angewandte Mathematik und Physik ZAMP, vol. 17, no. 1, pp. 189-191, 1966.

[2] K. R. Rajagopal, A. S. Gupta, and A. S. Wineman, "On a boundary layer theoryfor non-Newtonian fluids," International Journal of Engineering Science, vol. 18, no. 6, pp. 875-883, 1980.

[3] K. R. Rajagopal, "Boundary layers in non-linear fluids," in Trends in Applications of Mathematics to Mechanics, Pittman Monographs and Surveys in Pure and Applied Mathematics, M. D. P. M. Marques and J. F. Rodriques, Eds., vol. 77, pp. 209-218, Longman, New York, NY, USA, 1995.

[4] V. Aliakbar, A. A. Pahlavan, and K. Sadeghy, "The influence of thermal radiation on MHD flow of Maxwellian fluids above stretching sheets," Communications in Nonlinear Science and Numerical Simulation, vol. 14, no. 3, pp. 779-794, 2009.

[5] A. A. Pahlavan, V. Aliakbar, F. V. Farahani, and K. Sadeghy, "MHD flows of UCM fluids above porous stretching sheets using two-auxiliary-parameter homotopy analysis method," Communications in Nonlinear Science and Numerical Simulation, vol. 14, no. 2, pp. 473-488, 2009. 
[6] S. Karra, V. Prusa, and K. R. Rajagopal, "On Maxwell fluids with relaxation time and viscosity depending on the pressure," International Journal of Non-Linear Mechanics, vol. 46, no. 6, pp. 819-827, 2011.

[7] M. M. Heyhat and N. Khabazi, "Non-isothermal flow of Maxwell fluids above fixed flat plates under the influence of a transverse magnetic field," Proceedings of the Institution of Mechanical Engineers, vol. 225, no. 4, pp. 909-916, 2011.

[8] M. Athar, C. Fetecau, M. Kamran, A. Sohail, and M. Imran, "Exact solutions for unsteady axial Couette flow of a fractional Maxwell fluid due to an accelerated shear," Nonlinear Analysis, vol. 16, no. 2, pp. 135-151, 2011.

[9] L. E. Erickson, L. T. Fan, and V. G. Fox, "Heat and mass transfer problem on a moving continuous plate with suction or injection," Industrial \& Engineering Chemistry Fundamentals, vol. 5, pp. 19-25, 1966.

[10] L. J. Crane, "Flow past a stretching plate," Zeitschrift für angewandte Mathematik und Physik, vol. 21, pp. 645-647, 1970.

[11] B. C. Sakiadis, "Boundary layer behaviour on continuous solid surface I: the boundary layer equation for two dimensional and asymmetric flow," AIChE Journal, vol. 7, pp. 26-28, 1961.

[12] B. C. Sakiadis, "Boundary layer behaviour on continuous solid surface. II: the boundary layer on a continuous flat surface," AIChE Journal, vol. 7, pp. 221-225, 1961.

[13] S. J. Liao, "A new branch of solutions of boundary layer flows over an impermeable stretching plate," International Journal of Heat and Mass Transfer, vol. 48, pp. 2529-2539, 2005.

[14] S. Liao, "An analytic solution of unsteady boundary-layer flows caused by an impulsively stretching plate," Communications in Nonlinear Science and Numerical Simulation, vol. 11, no. 3, pp. 326-339, 2006.

[15] P. D. Ariel, "Extended homotopy perturbation method and computation of flow past a stretching sheet," Computers \& Mathematics with Applications, vol. 58, no. 11-12, pp. 2402-2409, 2009.

[16] M. S. Abel and M. M. Nandeppanavar, "Heat transfer in MHD viscoelastic boundary layer flow over a stretching sheet with non-uniform heat source/sink," Communications in Nonlinear Science and Numerical Simulation, vol. 14, no. 5, pp. 2120-2131, 2009.

[17] B. Raftari and A. Yildirim, "The application of homotopy perturbation method for MHD flows of UCM fluids above porous stretching sheets," Computers $\mathcal{E}$ Mathematics with Applications, vol. 59, no. 10, pp. 3328-3337, 2010.

[18] A. Yildirim and S. A. Sezer, "Non-perturbative solution of the MHD flow over a non-linear stretching sheet by HPM-Pad technique," Zeitschrift fr Naturforschung A, vol. 65, no. 12, pp. 1106-1110, 2010.

[19] B. Raftari, S. T. Mohyud-Din, and A. Yildirim, "Solution to the MHD flow over a non-linear stretching sheet by homotopy perturbation method," Science China, vol. 54, no. 2, pp. 342-345, 2011.

[20] M. Turkyilmazoglu, "Multiple solutions of heat and mass transfer of MHD slip flow for the viscoelastic fluid over a stretching sheet," International Journal of Thermal Sciences, vol. 50, no. 11, pp. 22642276, 2011.

[21] N. Bachok, A. Ishak, and I. Pop, "Unsteady three-dimensional boundary layer flow due to a permeable shrinking sheet," Applied Mathematics and Mechanics, vol. 31, no. 11, pp. 1421-1428, 2010.

[22] T. Fang, S. Yao, J. Zhang, and A. Aziz, "Viscous flow over a shrinking sheet with a second order slip flow model," Communications in Nonlinear Science and Numerical Simulation, vol. 15, no. 7, pp. 1831$1842,2010$.

[23] T. G. Fang, J. Zhang, and S. S. Yao, "Slip magnetohydrodynamic viscous flow over a permeable shrinking sheet," Chinese Physics Letters, vol. 27, no. 12, Article ID 124702, 2010.

[24] T. Fang and Y. Zhong, "Viscous flow over a shrinking sheet with an arbitrary surface velocity," Communications in Nonlinear Science and Numerical Simulation, vol. 15, no. 12, pp. 3768-3776, 2010.

[25] B. Raftari and A. Yildirim, "A new modified homotopy perturbation method with two free auxiliary parameters for solving MHD viscous flow due to a shrinking sheet," Engineering Computations, vol. 28, no. 5, pp. 528-539, 2011.

[26] C. Y. Wang, "Stagnation flow towards a shrinking sheet," International Journal of Non-Linear Mechanics, vol. 43, no. 5, pp. 377-382, 2008.

[27] A. Ishak, R. Nazar, and I. Pop, "Stagnation flow of a micropolar fluid towards a vertical permeable surface," International Communications in Heat and Mass Transfer, vol. 35, no. 3, pp. 276-281, 2008.

[28] N. Bachok, A. Ishak, and I. Pop, "Melting heat transfer in boundary layer stagnation-point flow towards a stretching/shrinking sheet," Physics Letters A, vol. 374, no. 40, pp. 4075-4079, 2010.

[29] A. Ishak, Y. Y. Lok, and I. Pop, "Stagnation-point flow over a shrinking sheet in a micropolar fluid," Chemical Engineering Communications, vol. 197, no. 11, pp. 1417-1427, 2010. 
[30] N. Bachok, A. Ishak, and I. Pop, "On the stagnation-point flow towards a stretching sheet with homogeneous-heterogeneous reactions effects," Communications in Nonlinear Science and Numerical Simulation, vol. 16, no. 11, pp. 4296-4302, 2011.

[31] H. Rosali, A. Ishak, and I. Pop, "Stagnation point flow and heat transfer over a stretching/shrinking sheet in a porous medium," International Communications in Heat and Mass Transfer, vol. 38, no. 8, pp. 1029-1032, 2011.

[32] R. Nazar, M. Jaradat, N. M. Arifin, and I. Pop, "Stagnation-point flow past a shrinking sheet in a nanofluid," Central European Journal of Physics, vol. 9, no. 5, pp. 1195-1202, 2011.

[33] Y. Y. Lok, A. Ishak, and I. Pop, "MHD stagnation point flow with suction towards a shrinking sheet," Sains Malaysiana, vol. 40, no. 10, pp. 1179-1186, 2011.

[34] F. G. Awad, P. Sibanda, S. S. Motsa, and O. D. Makinde, "Convection from an inverted cone in a porous medium with cross-diffusion effects," Computers $\mathcal{E}$ Mathematics with Applications, vol. 61, no. 5, pp. 1431-1441, 2011.

[35] Z. G. Makukula, P. Sibanda, and S. S. Motsa, "A note on the solution of the von Kármán equations using series and Chebyshev spectral methods," Boundary Value Problems, vol. 2010, Article ID 471793, 17 pages, 2010.

[36] S. S. Motsa, "New algorithm for solving non-linear BVPs in heat transfer," International Journal of Modeling, Simulation \& Scientific Computing, vol. 2, no. 3, pp. 355-373, 2011.

[37] S. S. Motsa, P. Sibanda, and S. Shateyi, "On a new quasi-linearization method for systems of nonlinear boundary value problems," Mathematical Methods in the Applied Sciences, vol. 34, no. 11, pp. 1406-1413, 2011.

[38] S. Shateyi and S. S. Motsa, "Variable viscosity on magnetohydrodynamic fluid flow and heat transfer over an unsteady stretching surface with Hall effect," Boundary Value Problems, vol. 2010, Article ID 257568, 20 pages, 2010.

[39] C. Canuto, M. Y. Hussaini, A. Quarteroni, and T. A. Zang, Spectral Methods in Fluid Dynamics, SpringerVerlag, Berlin, Germany, 1988.

[40] W. S. Don and A. Solomonoff, "Accuracy and speed in computing the Chebyshev collocation derivative," SIAM Journal on Scientific Computing, vol. 16, no. 6, pp. 1253-1268, 1995.

[41] J. A. C. Weideman and S. C. Reddy, "A MATLAB differentiation matrix suite," Association for Computing Machinery, vol. 26, no. 4, pp. 465-519, 2000.

[42] L. N. Trefethen, Spectral Methods in MATLAB, Society for Industrial and Applied Mathematics (SIAM), Philadelphia, Pa, USA, 2000. 


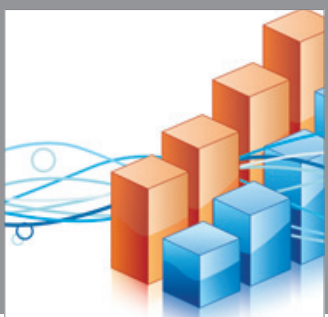

Advances in

Operations Research

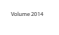

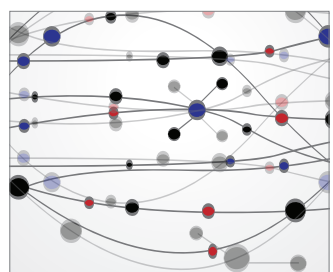

\section{The Scientific} World Journal
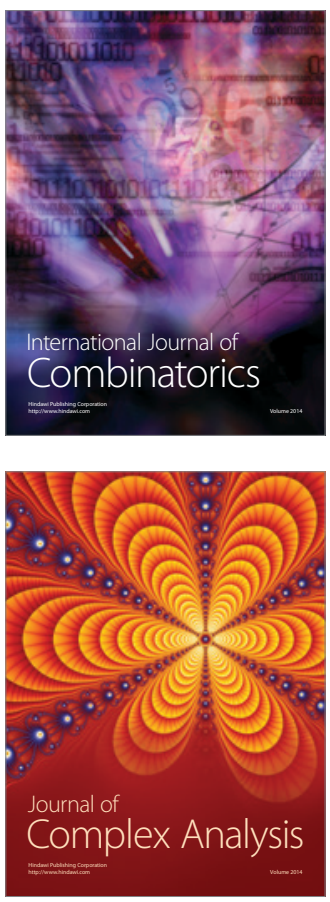

International Journal of

Mathematics and

Mathematical

Sciences
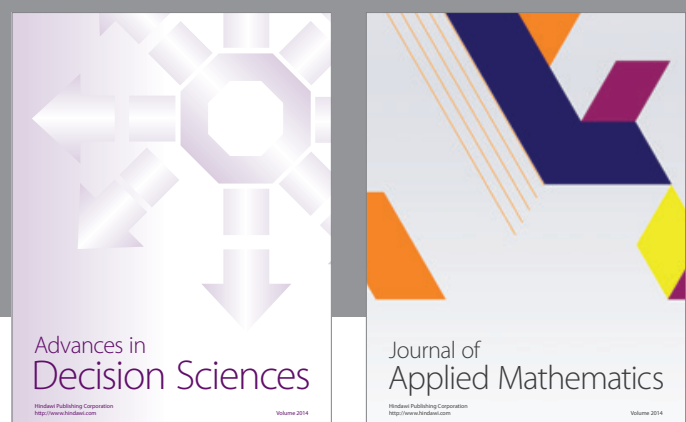

Journal of

Applied Mathematics
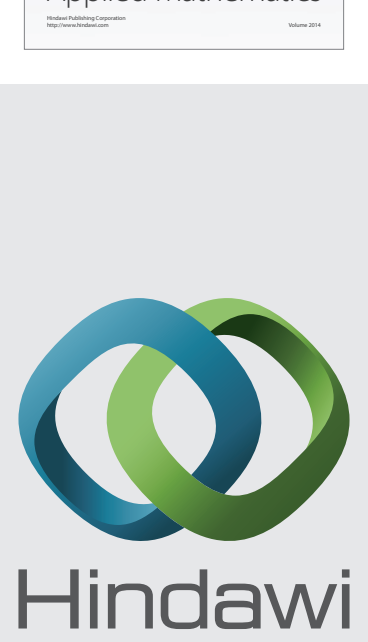

Submit your manuscripts at http://www.hindawi.com
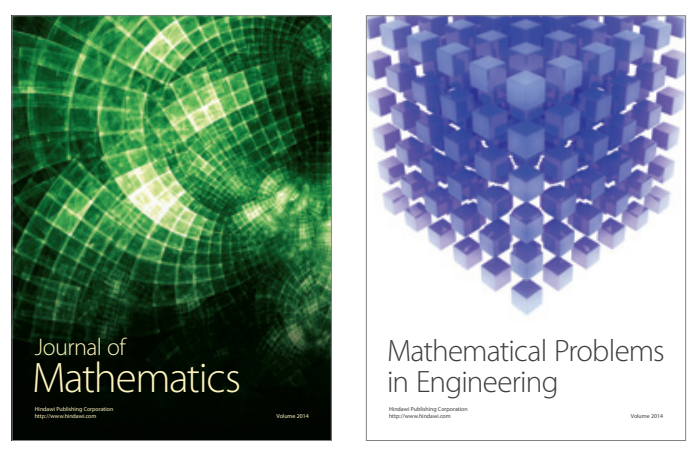

Mathematical Problems in Engineering
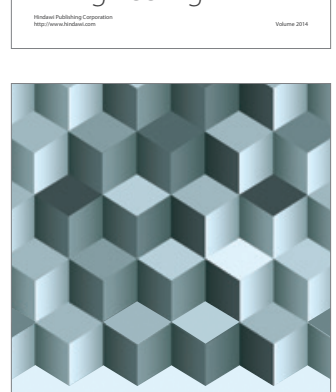

Journal of

Function Spaces
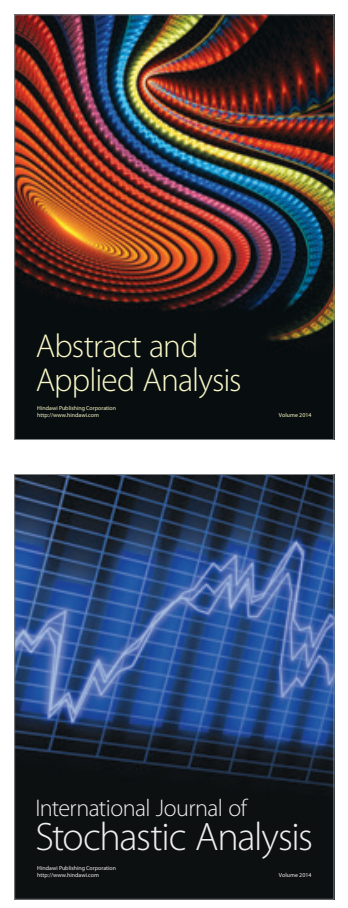

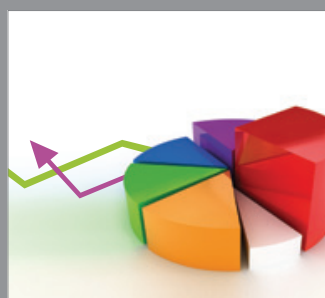

ournal of

Probability and Statistics

Promensencen
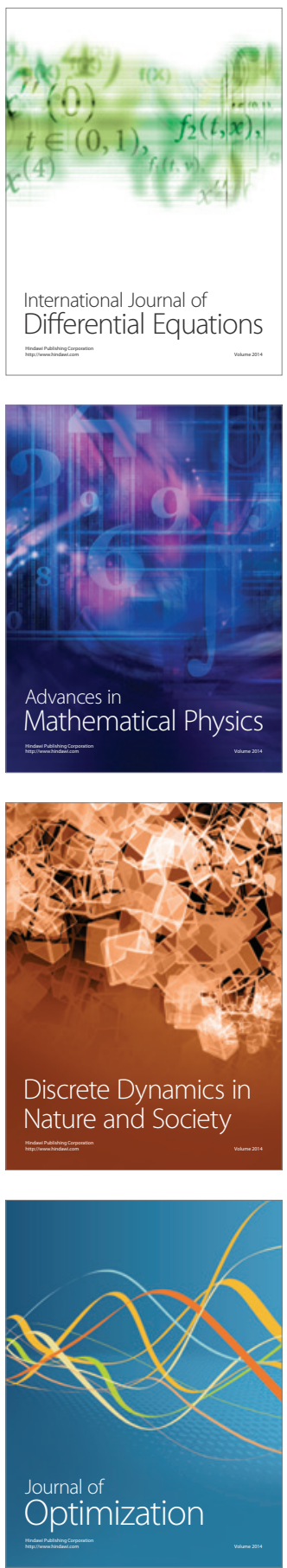